$\mathbb{T}$ periodica polytechnica

Mechanical Engineering

$54 / 2$ (2010) 71775

doi: 10.3311/pp.me.2010-2.02

web: http://www.pp.bme.hu/me

(c) Periodica Polytechnica 2010

RESEARCH ARTICLE

\section{Wear simulation of a reciprocating seal by global remeshing}

\author{
Nándor Békési / Károly Váradi
}

Received 2010-11-31

\begin{abstract}
Tribological modeling of elastomeric parts has high importance in engineering practice due to their widespread industrial use. Generally, the experimental investigation of the wear behavior is time consuming and expensive, which led to the development of numerical techniques. The common finite element method (FEM) based wear simulation techniques are usually limited to the top layer of the elements in the FE mesh. This can be insufficient in case of elastomers because of their high deformation.In order to model wear that is larger than the elements of the FE mesh, a wear simulation procedure was developed using global remeshing. By this new wear simulation technique, a reciprocating sliding seal was analyzed. Contact pressure distribution as well as the resultant sealing force was evaluated during the wear process. It was concluded that the wear reduced the contact pressure peaks along the ridges of the reciprocating seal. Around the lip similar tendencies were obtained during the simulated wear process. The results showed that the method is suitable for modeling wear even if it is three times larger than the element size in the vicinity of the contact area.
\end{abstract}

\section{Keywords}

FEM $\cdot$ wear simulation $\cdot$ seal

\section{Nándor Békési}

Department of Machine and Product Design, Budapest University of Technology and Economics, Múegyetem rkp. 3, H-1111 Budapest, Hungary e-mail: bekesi.nandor@gt3.bme.hu

\section{Károly Váradi}

Department of Machine and Product Design, Budapest University of Technology and Economics, Múegyetem rkp. 3, H-1111 Budapest, Hungary e-mail: varadi@eik.bme.hu

\section{Introduction}

Even though tribology is traditionally an experimental science, in the last decades the numerical simulation of tribological processes, like wear became popular. There were several studies using different numerical methods for calculating wear. Serre et al. in [1] used the boundary element method (BEM) to determine the contact pressure distribution for further wear calculations. Fillot et al. in [2] applied the method of discrete elements, which made it possible to model the effects of wear debris as third body of the tribological system. Páczelt and Mróz in [3] showed a variational approach for wear analysis. However, the most popular numerical technique in engineering is the finite element method (FEM). The breakthrough in numerical wear simulation was the technique presented by Pödra and Andersson [4]. In this iterative method, firstly the contact pressure distribution is determined by FEM and the nodal wear increments are calculated from the wear equation of Archard [5]. Then the contacting nodes are moved with respect to the nodal wear values. Finally the FE contact calculation is carried out again with the modified mesh and the cycle is repeated according to the simulated wear process. Eleôd in [6] also used the finite element method, but instead of moving the nodes, the damaged elements became deactivated based on a fatigue damage criterion. Kónya and Váradi in [7] improved the method of Pödra and Andersson in order to consider heat generation and time dependent material properties during the wear simulation. Despite the widespread use of the Pödra-Andersson method, the wear simulation is highly limited; only the top layer of elements can be worn. This limitation does not affect the usability of the method in case of relatively hard materials such as metals or ceramics, since minimal wear can have a great effect on the contact area and pressure distribution and thus on the performance of these parts (e.g. bearings). In case of rubber parts, wear in the magnitude of some $\mu \mathrm{m}$ does not change the contact conditions significantly. Furthermore the wear needed for a rubber part to malfunction is much greater than those of metal parts; therefore the wear of the top layer is insufficient in rubber applications. To increase the volume of the wear to be modeled, the size of the elements can be increased; however it is not recommended, 
since it decreases the accuracy of the calculation. In the present paper authors propose a method to simulate wear regardless of the element size.It will be shown that this method (with global remeshing) can model the material loss due to wear even in a scale comparable with the size of the part.

\section{The investigated application}

In order to demonstrate the method proposed in this paper a wear simulation study of a reciprocating sliding seal (Fig. 1) is presented. In the investigated application a rubber seal is coupled with an aluminum rod (diameter: $\varnothing 22.2 \mathrm{~mm}$ ). The system is lubricated by hydraulic fluid type Hydrulan 407-1 of BASF (Ludwigshafen,Germany).

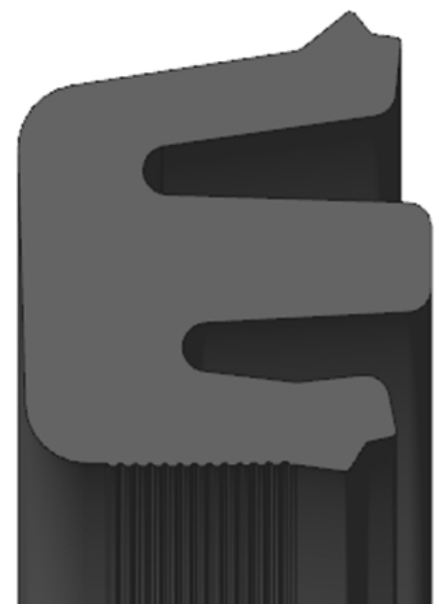

Fig. 1. Section view of the investigated reciprocating seal

Fig. 2 shows a photograph of the worn surface of a similar reciprocating seal (the photograph was provided by the manufacturer of the seal, TRW Automotive, Navarra,Spain). It can be seen that the wear is non-uniform. The enlarged area reveals a wear phase, in which the ridges of the seal are almost completely worn, while in other regions the ridges are clearly visible.

In this case study, the seal was modeled as an axisymmetric component using MSC.MARC finite element software package.The counter-surface was modeled as rigid body, since its elastic modulus is some orders of magnitude larger than the elastomer material of the seal. The seal was mounted axially by fitting it in the housing, which was considered ideally rigid. The rod was moving with alternating motion at a speed of 20 $\mathrm{mm} / \mathrm{s}$ with $9 \mathrm{~mm}$ amplitude. The contour of the seal section was modeled by line segments (Fig. 3). A fine approximation in the vicinity of the lip as well as the ridges was required; in the region of the ridges and the lip the average length of the line segments was $10 \mu \mathrm{m}$.

The seal section was meshed by the built-in automatic meshing procedure using three-node axisymmetric triangular finite elements (Fig. 4). In the FE calculations the interference fit between the seal and the rod was also taken into consideration: the unloaded inner diameter of the seal was $1.8 \mathrm{~mm}$ smaller than the diameter of the rod.This caused the seal to be stretched in load step 1. In the next step the alternating motion was mod-

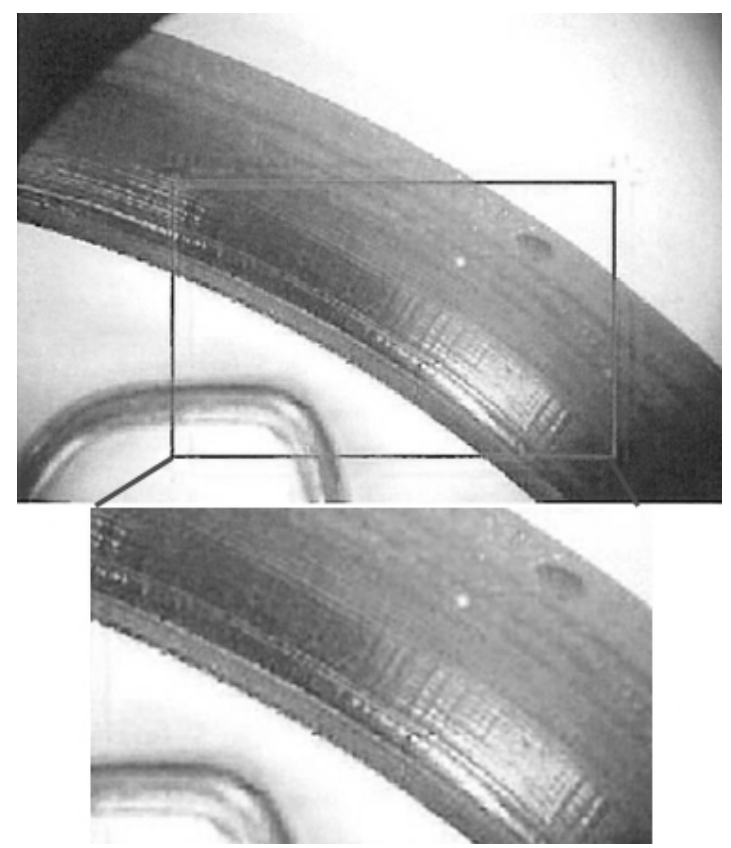

Fig. 2. Photograph of worn surface of a reciprocating sliding seal

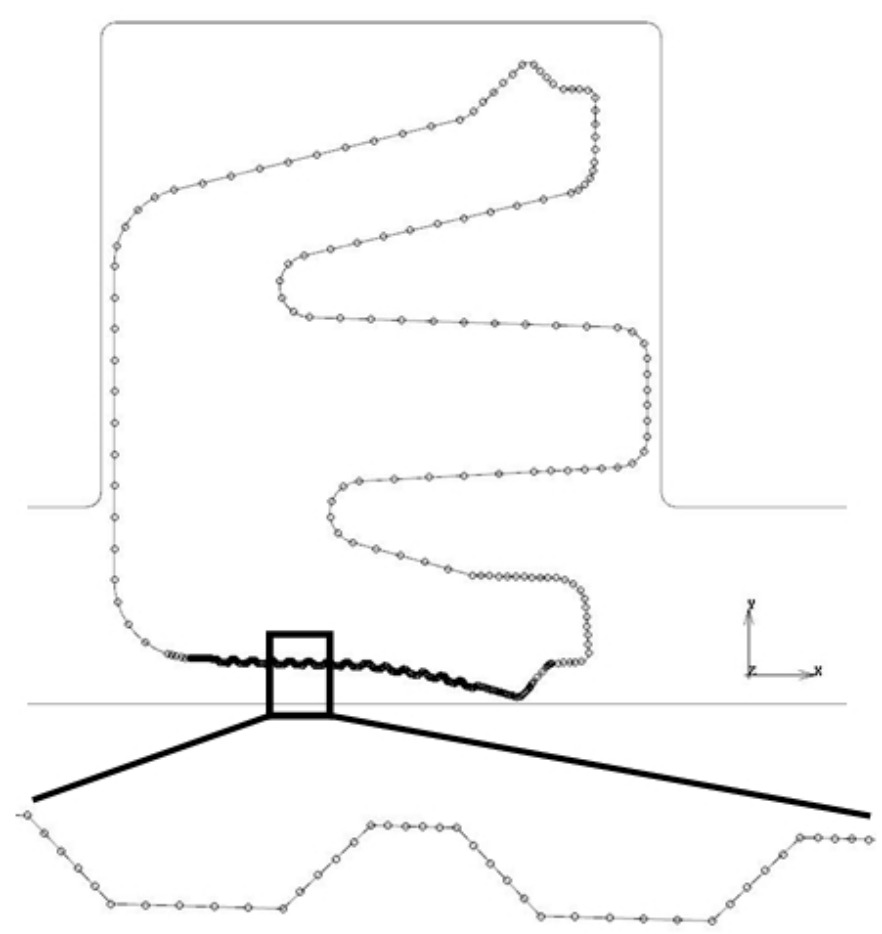

Fig. 3. The geometry of the seal consisting of line segments and points

eled considering the friction during the wear simulation. According to the working conditions, in the inward strokes of the rod a pressure load of $p=12 \mathrm{MPa}$ was applied on the right side of the seal, modeling the sealed pressure. There was no pressure applied in the outward strokes. Between the seal and the rod a prescribed coefficient of friction with a value of $\mu=0.1$ was defined in order to model the lubricated friction [8]. The material properties of the seal was modeled by a 15-term generalized Maxwell model with a hyperelastic Mooney-Rivlin element $\left(\mathrm{C}_{10}=289.33 \mathrm{MPa}\right.$ and $\left.\mathrm{C}_{01}=72.33 \mathrm{MPa}\right)$. The material model used is described in details in [9]. 


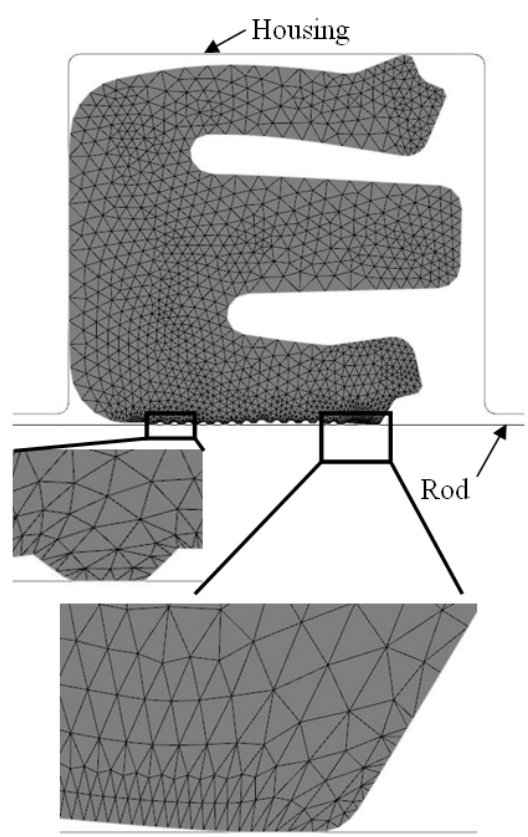

Fig. 4. Deformed shape of the seal in the first outstroke (without pressure). The curves represent the rigid bodies (the rod and the housing). The element size varies from $10 \mu \mathrm{m}$ to $200 \mu \mathrm{m}$

\section{The wear simulation procedure}

In the wear simulation process, the FE mesh was created based on the line segments describing the geometry.The automatic mesher was set to create elements of different sizes, so the elements in the vicinity of the contact zone were smaller than those deep inside the material. In the initial mesh approximately 4000 elements were distributed in a way that the regions, that are important for the wear calculations, were modeled more accurately with the small elements. Even so the total number of the elements remained in a reasonably low range, so the CPU time for one calculation was short enough to handle the iterative simulation process.

The flowchart of the simulation can be seen in Fig. 5. In the first step the FE mesh was created based on the initial geometry. After adjusting the simulation parameters (coefficient of friction, sliding velocity, material properties, applied pressure, time increment, etc.) the contact calculation was run. In the first stroke the rod was moving rightward. After the FE contact calculation, the wear increment was determined based on the stress distribution. The $\Delta h_{i}$ nodal wear of the $i$-th node in the contact area by Archard [5] is defined as:

$$
\Delta h_{i}=W_{s} p_{i} v \Delta t
$$

where $W_{s}$ is the specific wear rate, $p_{i}$ is the nodal contact pressure at node $i, v$ is the sliding velocity, $\Delta t$ is the time increment.

The specific wear rate was set to $5.5 \mathrm{E}-6 \mathrm{~mm}^{3} / \mathrm{Nm}$, which is about two orders of magnitude higher than it is common for this type of applications. However, it was necessary to accelerate the wear process in order to get significant wear in reasonable CPU time. The surface nodes were attached to the contour points, so if a point was moved the attached node would also move with re-

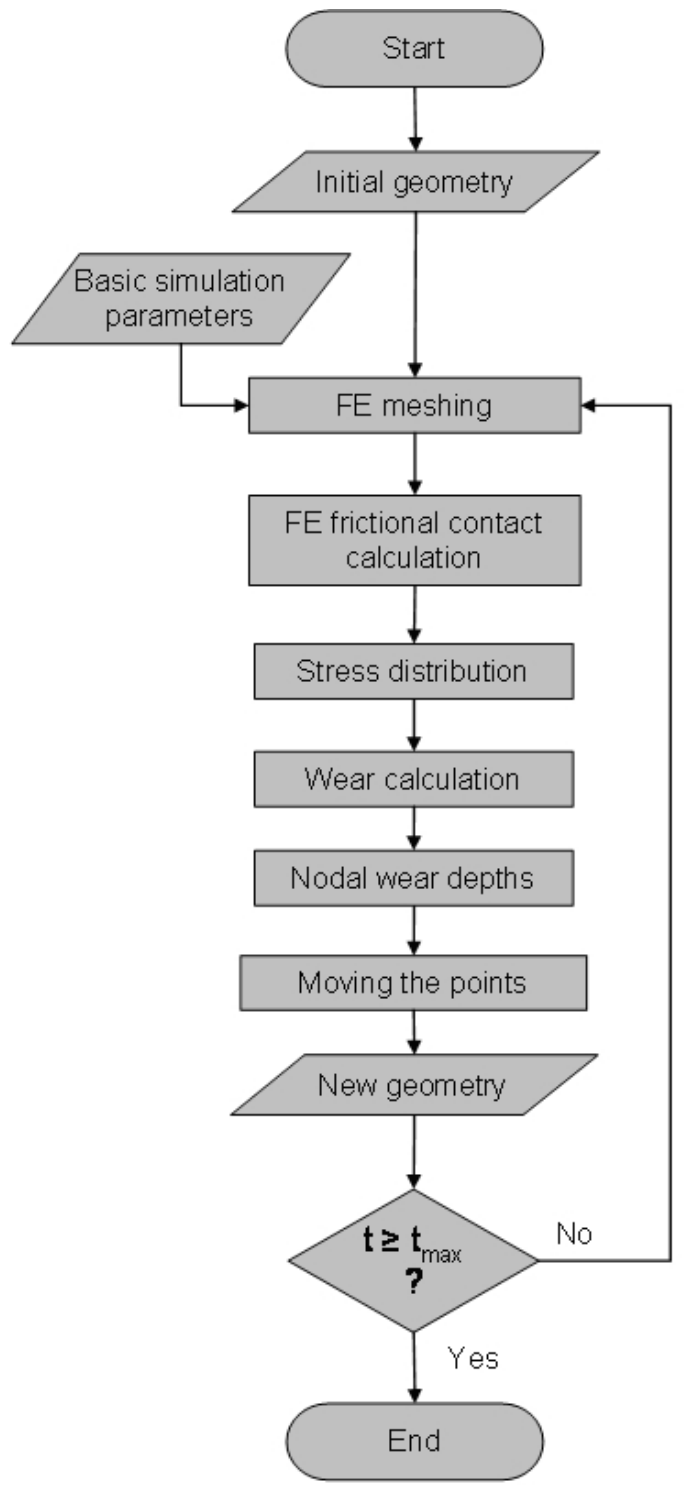

Fig. 5. The flowchart of the wear simulation process.

spect to the nodal wear value of the attached node. After moving the points, the whole FE mesh was deleted. Based on the new geometry the automatic mesher created the new elements and the cycle ran. over again. The direction of the rod motion was changed in each cycle, so one simulation cycle represented one outward (left) or one inward (right) stroke. The applied pressure was also changed stroke by stroke, as for the inward strokes the working pressure of $2 \mathrm{MPa}$ was applied, while in the outward strokes the working pressure was turned off in the simulation process.200 simulation cycles were calculated in the frame of this study.

\section{Results and discussion}

Fig. 6 shows the deformed shape of the seal in the first outward stroke, when the seal was not pressurized. The resulting contact pressure comes from the stretching of the seal on the rod. It can be seen that the contact area is reduced: only five ridges on the left side, one on the right side and the lip are in contact with the rod. The maximum of the contact pressure can be observed at the lip.The values of the contact pressure are gen- 
Fig. 6. Deformed shape of the seal in the first outward stroke (without applied pressure) and its contact pressure distribution.

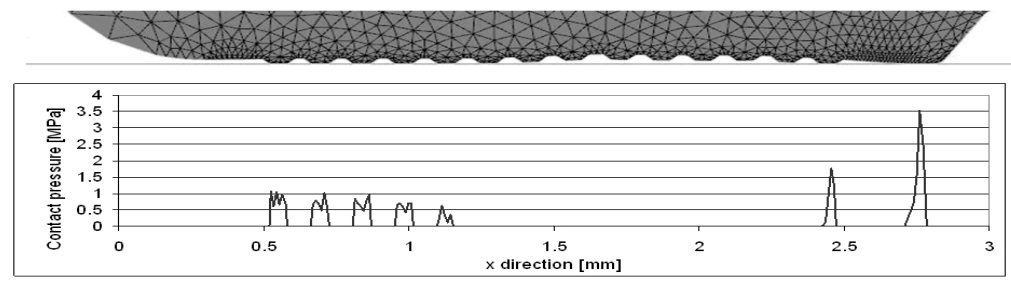

Fig. 7. Evolution of the calculated worn profile after $0,50,100,150$ and 200 cycles of the simulation in inward strokes ( $p=2 M P a$ pressure applied) and the corresponding contact pressure distributions along the axis, respectively.
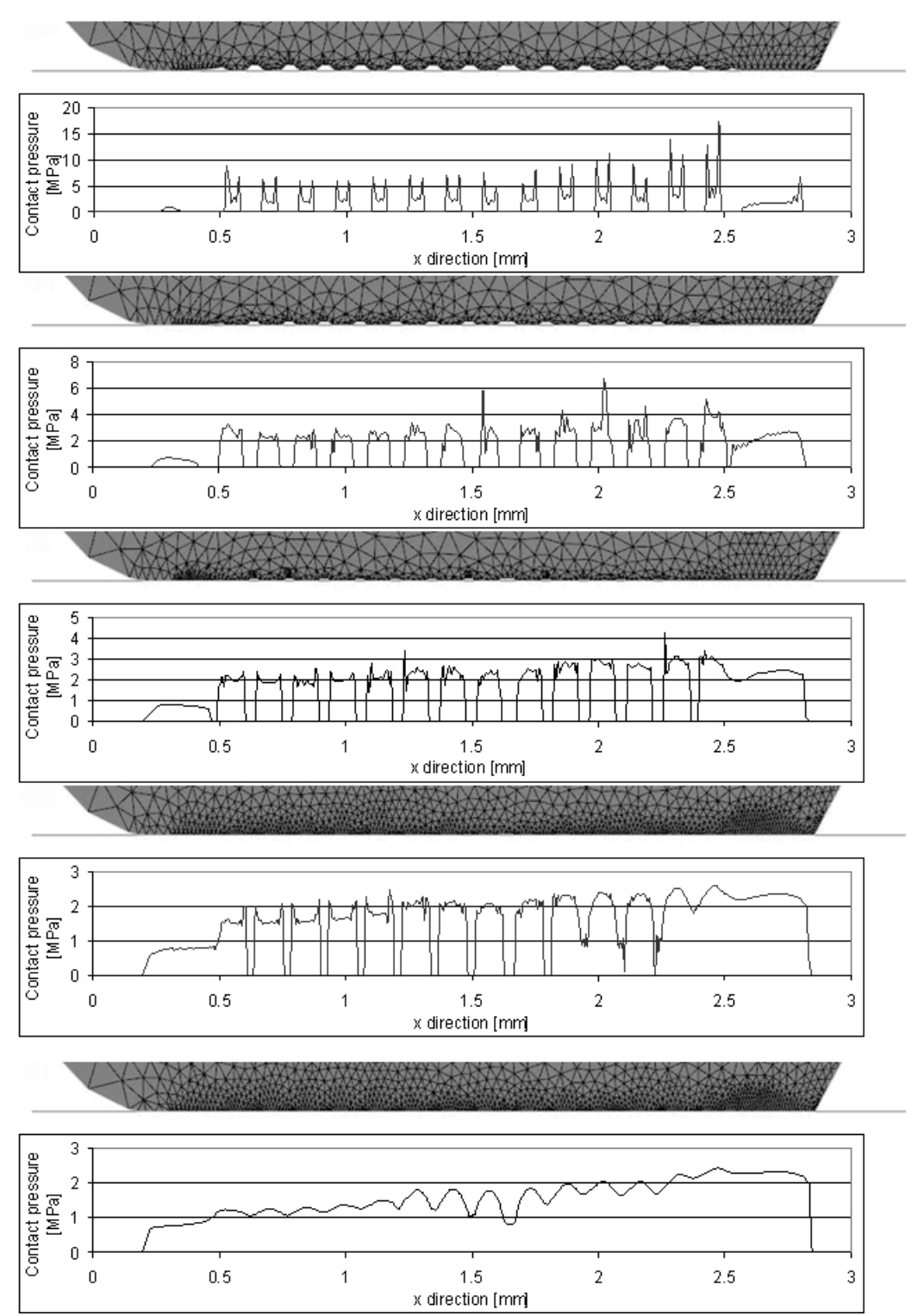

erally low, since there is no working pressure applied to press the seal surface to the rod.

The calculated worn profiles of the seal are shown in Fig. 7 after $0,50,100,150$ and 200 cycles of the simulation.It can be seen that the left side ridges of the seal and the lip edge wear first. Fig. 7 also shows the contact pressure distributions in the investigated wear phases. Note that the FE mesh is different in each state, since the model was remeshed in every cycle; however the element sizes are distributed identically. It should mentioned that the total simulated wear depth reaches $30 \mu \mathrm{m}$ in some regions (e.g. at the lip), which is three times higher than the size of the elements in the contact area.This wear depth is so large that the Pödra-Andersson method can not be applied here.Based on the change of contact pressure distribution the followings can be established. The area of contact increased, while the maximum values of the contact pressure decreased. This phenomenon can also be seen in Fig. 8 for the contact pressure distribution of the lip over the wear process. One can see that the seal at the beginning has about three times higher contact pressure than later. The pressure reduction is caused by the wear process, which also increases the contact area. It is remarkable that at the left side of the lip the contact pressure is increasing at first, and then slightly decreasing. It can be explained by the wear of the lip. As the lip has the highest contact pressure in the beginning of the simulation, it will suffer the most severe wear in the first cycles. As the lip wears, the contact pressure distribution becomes flatter, which causes the slight increase in the lower pressure region. Later this mostly uniform contact 
pressure remains, only the average pressure decreases.

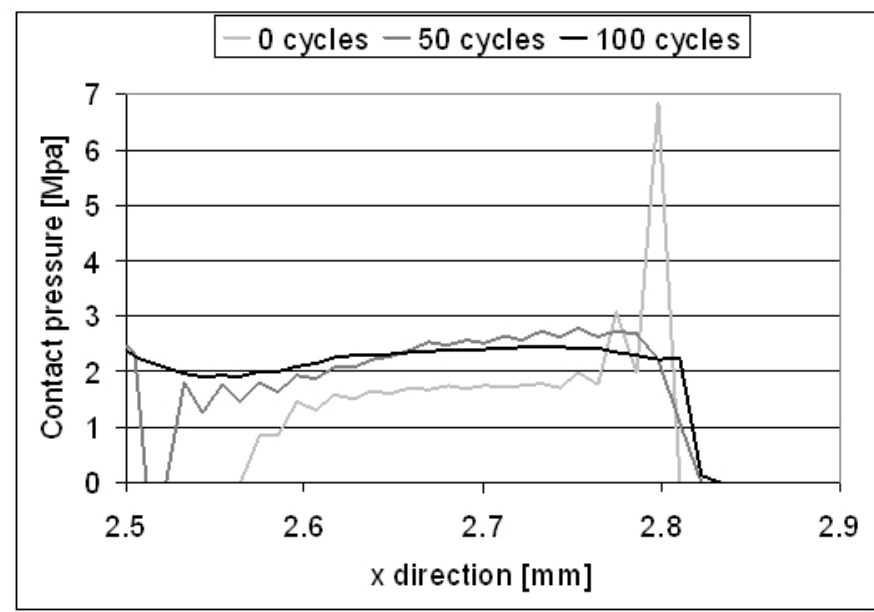

Fig. 8. The change of the contact area and the contact pressure distribution at the lip over the wear process

The resultant sealing force was calculated by integrating the contact pressure distributions (Fig. 9). One can see that the values tend to decrease slightly. It can be explained by the reducing interference of the parts due to the wear.

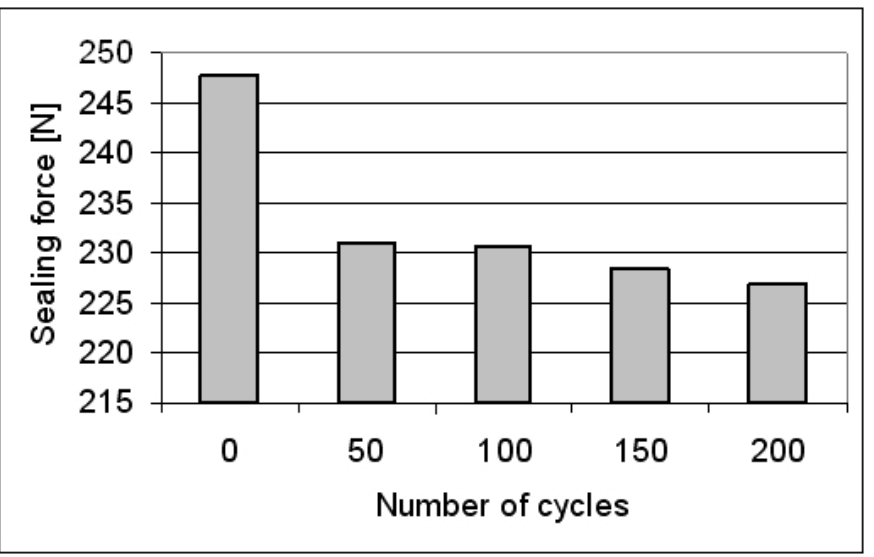

Fig. 9. The resultant sealing force over the wear process

\section{Conclusions}

In order to model wear that is larger than the elements in the FE mesh, a wear simulation procedure with global remeshing was developed. The simulation technique was based on the Pödra-Andersson approach [4], but instead of simply moving the contacting nodes according to the determined nodal wear values, the calculated new geometry was remeshed in every simulation cycle. This concept required an accurate modeling of the seal contour especially in the vicinity of the contact area. This way not only the top layer of the elements can be worn, but even the wear bigger than the elements can be simulated. The proposed wear simulation method was demonstrated in the analysis of a reciprocating sliding seal. The results show that during the wear process the contact pressure distribution basically changed. The peak values decreased as the wear progressed and the area of contact increased. At the same time the resultant sealing force slightly decreased. Finally it needs to be mentioned that the presented method can be easily applied in other applications (in 2D and 3D) not only in the ones similar to the sliding seal demonstrated in this paper.

\section{References}

1 Serre I, Bonnett M, Pradeilles-Duval R, Modelling an abrasive experiment by the boundary element method, Comptes Rendus de 1'Academie des Sciences Paris Série II b, 329, (2001), 803-808.

2 Fillot N, lordanoff I, Berthier Y, Simulation of Wear Through Mass Balance in a Dry Contact, ASME Journal of Tribology, 127, (2005), 230-237.

3 Páczelt I, Mróz Z, Variational approach to the analysis of steady-state thermo-elastic wear regimes, International Journal for Numerical Methods in Engineering, 81, (2010), 728-760.

4 Pödra P, Andersson S, Simulating sliding wear with finite element method, Tribology International, 32, (1999), 71-81, DOI 10.1016/S0301679X(99)00012-2.

5 Archard J F, Contact and rubbing of flat surface, J Applied Physics, 24, (1953), 981-988.

6 Eleöd A, Numerische Tribologie: Strukturveränderungs- und Verschleißsimulation mit Hilfe der Finiten Elemente Methode, Tribologie und Schmierungstechnik, 55, (2008), 17-22. in German.

7 Kónya L, Váradi K, Wear simulation of a polymer steel sliding pair considering temperature and time dependent properties, Tribology and Interface Engineering Series, 55(7), (2008), 130-145.

8 Békési N, Váradi K, Experimental and numerical evaluation of lubricated friction of EPDM rubber, Periodica Polytechnica-Mechanical Engineering, 53(2), (2009), 1-5.

9 Pálfi L, Goda T, Váradi K, Theoretical prediction of hysteretic rubber friction in ball on plate configuration by finite element method, Exp. Polym. Lett, 3(11), (2009), 713-723, DOI 10.3144/expresspolymlett.2009.89. 